\title{
Pairing Display and Spring and Summer Flights of the Mallard
}

\author{
By ALEX DZUBIN, \\ Canadian Wildlife Service, Saskatoon, Sask.
}

Mallards are found in Saskatchewan during the larger part of the year. Their presence may first be noted late in March as they move in large flocks onto the grassland and parkland breeding grounds. Later in the season feeding groups of young and adults remain until continued freezing weather forces them out in November or December. This article is an attempt to describe the courtship postures and aerial flights which are so often seen during the relatively short breeding season.

Each year, starting in October and continuing through March of the following year, groups of Mallard drakes court females prior to pairing. Although much of this pairing occurs on the southern wintering areas of the United States, courting groups do occur in our province early in the fall, and again during spring migration. Such groups can be easily identified if one watches their general behaviour on the water. Courting groups are usually made up of from four to fifteen drakes and one to five hens. Usually, however, five or six drakes court one female.

Characteristically the following postures can be identified in the courting drakes (adapted after Lorenz, 1941). These are given in the order in which they usually occur as a group of drakes swim about an unmated hen.

1. Mock preening - A drake runs his bill quickly against the underside of his slightly lifted, wing so that a loud "Rrr" sound can be heard.

2. Preliminary shaking - Each drake swims about nervously with his head and neck tucked into his body; no white neck ring can be seen. The head feathers are ruffled and the drake may then thrust his head upward and shake his entire body while partly lifting it out of the water. This shaking occurs regularly and with increased intensity. Following this one of the following three postures occur.

3. Grunt Whistle - The drake's bill is thrust down into the water and then he moves his body while his head is still low, appearing to draw his bill upward along his breast. When the neck is strongly curved there is a loud sharp whistle followed by a deep grunt, the head straightens up again, and the body sinks back.

4. Head-up Tail-up - With a loud whistle the drake thrusts his head with indrawn chin backwards and upwards, and at the same time curves his rump upwards, so that the whole bird looks short and high. This posture is very brief. The head remains high and the bill is pointed toward a female in the group. Following this the drake swims swiftly over the surface of the water with head and neck held close to the surface. He then lifts his head and turns the back of it toward the female. The hen may follow a certain drake for a short distance away from the group.

5. Down-up Movement - A drake quickly thrusts his bill into the water and in the next movement jerks up his head without lifting his breast, which is still low in the water. When the head is highest a whistle is emitted and a small stream cf water may follow the bill up. Following this, the drake gives a short harsh call, a nasal "raehb.'

Hens invariably initiate a courting group by their actions. They swim nervously about with head and neck low over the water, occasionally giving short quacks. Hens continus this neck stretch and quackin through the previously described courting display of the males. If fact, should the hen suddenly sto these movements, the drakes als stop and do not complete all of th display postures. Hens may als swim after a drake for a short dis lance, moving their head and bi quickly backwards toward the sides, giving the "inciting call" be: described as "queggege - ggegge ggeggegg." This usually occurs aft the head-up tail-up posture of tr drake. Drakes occasionally "figl 
while courting, one grasping the ther's chest feathers and tugging. The whole courting group may also ise in the air, fly about for a ninute and resettle a short distance way.

The entire sequence of the drake's postures may be given, at the height of courtship intensity, in a period of ess than two minutes. However, postures are given over and over gain. Courting groups break up ffter live or ten minutes of display uut may regroup again at the end of shor't rest period. After a number f such pairing displays a hen may end to associate with a particular trake. This is the first indication of he formation of the pair bond, which probably strengthens through ontinued association. The pair remains together as a unit and later nigrates north.

Prior to copulation a pair of Malards will face each other and both bump their heads and necks up and lown some ten times. Then the emale stretches her neck and head ow into the water and the male nounts. After the coition the drake lings back his head, gives a loud whistle and swims about the female n a half circle, with his head held ow on the water.

During the spring and summer mall flocks of Mallards are seen lying in the air in apparent migraion, display or pursuit. If these locks are watched closely one can ee that their flying direction may lot be consistent, that the number f males and females vary and that ome flocks fly slowly while others hove over the countryside in a ery erratic manner. The following liscussion attempts to classify and nterpret some of these aerial flights.

\section{Migrating Flight}

With the coming of the first few pring days Mallards migrate north 1 flocks varying in size from a ew pairs to several hundred birds. However, small groups of from ight to forty birds are characterisically seen. These migrating flocks ly in a northerly direction at varyng distances above the ground, ome as close as 200 feet and others vell above 5,000 feet. They fly at ight during the early morning and vening hours and less commonly hrough the day.
Most of the groups are made up of pairs, although small groups of unmated males may accompany the pairs. In any flock each female is invariably followed by a male. Individual pairs can easily be picked out for the drake and hen remain very close to each other in flight and on the ground. Occasionally Pintails and Baldpate mix with these flocks moving north.

After the flocks reach the breeding grounds individual pairs gradually drift away from the main body of birds. Each pair settles and remains on a small water area or portion of a marsh prior to nesting.

\section{Spring Courtship Flight}

Within resting migrating flocks, a few of the hens seem to be only loosely paired with their drakes and these females may initiate a so-called courting flight. A number of bachelor drakes crowd about the hen giving courting postures No. 2 and 3 (i.e. preliminary shaking and $\mathrm{grunt}$ whistle.) Often their persistent crowding forces the female to rise and the drakes follow. Some five to fifteen drakes may join in the chase after the single female. The group flies back and forth and up and down over the countryside in a very erratic manner for a period varying from five to ten minutes. Females occasionally give the "inciting call" during the chase. After a few minutes some of the drakes may break away, and later the remainder cf the group settles in another pond. It has not yet been determined whother the female chooses another mate during these flights or whether she is merely try.ing to elude the persistent bachelors. These flights are usually seen from the first part of April to the middle of May.

\section{Continuous Call}

During quiet warm mornings and evenings in early April mated females start to give a single loud monotone call best described as "quaqua-qua-qua" etc. About 16 to 20 calls are given per ten second period but length of the calling period is usually not very consistent. Apparently this is an indication of some inner restlessness in the bird and perhaps of a desire to begin laying eggs. While calling the female appears nervous, flying about the countryside from one water area to another or merely swimming or fly- 


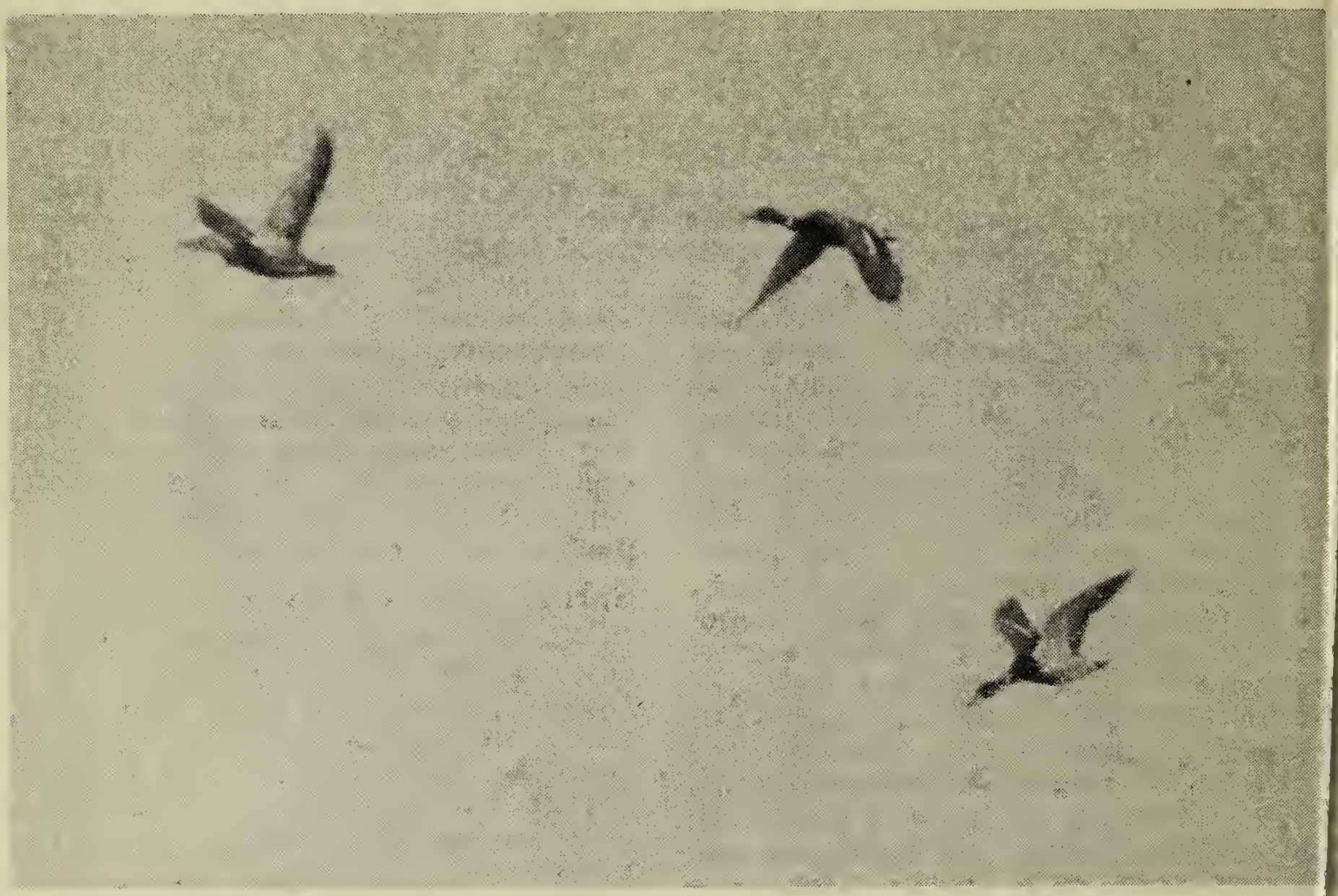

MALLARD TERRITORIAL PURSUIT

ing about a single slough. She may even visit nesting cover with her drake. Females give this call at sunrise and sunset but are sometimes heard through the day as well. The continuous call is usually heard after April 10th and a few females give it until the middle of May. Hens call most persistently during a short period prior to egg laying.

\section{Territorial Pursuit}

Until the time that mated females give the continuous calls pairs are relatively gregarious, that is, they still associate with each other without too much apparent friction. However, as soon as the female starts to call, the drake becomes aggressive and chases all pairs and females which attempt to land near him or his female. His attack is usually directed toward the intruding female of a pair and only rarely toward the male. In this way he keeps a small area of marsh or slough cleared of other Mallard pairs. Pairs of other species are rarely attacked. This protected area, known as a territory, is the area from which the female flies to her nest and upon which the drake awaits his female. The nest itself is not necessarily within the territory, but may be up to one-half mile away. (The whole problem of
Mallard territories is unduly com plex because of some overlap these protected areas. For a mor complete but not necessarily corre discussion see Dzubin, 1955).

Drakes chase females of intrudir pairs for distances up to 200 yar during the pre-nesting period ar well over a half mile during tl early incubation period. A typic flying territorial pursuit contai three birds. The territorial dra chases the female of the transgres ing pair and both these birds tw and turn over the countryside. T drake of the female being chas follows some fifty feet behind the two birds. The female may give $t$ inciting call of courtship or occ. sionally a "repulsion call" which w 1 be described later. After the ch: the territorial drake returns to $s$ territory, the drake of the tra: gressing pair rejoins his female $=x$ they alight elsewhere. Occasions $y$ two or three drakes may sim taneously launch territorial pursis against the same female of a $p$, especially if their territories are c] e to each other. T'erritorial purs is are commonly seen from April $1 \mathrm{~h}$ to the middle of July, most of $\operatorname{tr} n$ occurring in late April and $e_{i} y$ May. 
As previously mentioned, females art to settle in nesting cover after arting the continuous call. After isiting nest cover for five or six ays a nest site is chosen and the male starts to lay her eggs. Each orning, sometime between 5:00 to 00 a.m., the pair leaves the tertory and flies low over the nest te, and the female drops into the ver near the nest site while the ake returns to. the territory or me other nearby water area. The male usually completes laying by bon and thereafter the pair feed ad rest. Each morning another egg laid until eight to thirteen eggs mplete the clutch.

During the egg-laying period the rake is always with the female hen she is off the nest. When the male starts to incubate after the st egg is laid, her drake joins other rakes whose females are also inabating, and they form small groups ho feed and rest most of the day. ach morning and evening the drake isits his territory and awaits the male. If she returns he remains ert while she feeds. Toward the id of the second week of incubation e drake's attachment to the female anes and he spends more and more me with other males. Later these roups retire to lakes where the akes moult. Practically no Ma-lard fake actually sees his own brood.

\section{roup Chases}

After the drakes gather into small roups during the early incubation riod they regularly chase any inibating female flying off her nest, tempting to force her down and pe her. An incubating female set con by a group of drakes gives a ery harsh "repulsion call," a broken ries of single "gaeck" sounds, harply uttered like a cough (Lor12 , 1941). With this call the head id back feathers rise, the upper bill bent upward, and the head is awn deeply onto the neck. The female may drop down onto the ground and make short hopping flights over the countryside, always pursued by the group of drakes. All such flights do nct necessarily culminate in the successful rape of the duck by the drakes. Many drakes leave the group after a short chase, while others join in. Occasionally female dives into heavy bush to escape her pursuers.

From three to twenty drakes may harry a single female. These flights are most commonly seen during May and June, and less commonly in July when the groups of drakes begin to leave the breeding grounds to moult.

\section{Summer Courtship Flight}

A chase which occurs cixing May and June and is similar to the one described above may be a courtsinip flight. Fromi three to thirty males may follow a female slowly over the countryside. The female does not give the repulsion call but remains silent and occasionally hovers for a time low over the ground. It is thought that females who lose their clutches late in incubation and whose drakes have already left for the moulting lakes lead such flights. In order to re-nest these females may initiate courting parties to choose another mate. Females who lose their clutches to predators early in incubation are still associated with their drake and need not initiate a courtship flight. However, these hypotheses must be subject to further corroboration.

There is a definite chronological overlap of most of the aerial flights described. Two or more may occur over the same breeding habitat on the same day. This is due to the fact that not all pairs nest at the same time. However, each flight can be keyed if one watches the behaviour of the female and the accompanying drakes.

I w:uld like to acknowledge with thanks the financial aid received from the National Research uncil of Canada and the Wildlife Management Institute of Washington for a study on Mallard olcgy in Manitoba from 1952 to 1955 . The Canadian Wildlife Service has financed all my rk in Saskatchewan. I would also like to thank my colleague, Mr. J. B. Gollop, for his help criticizing the original manuscript.

LITERATURE CITED

ZUBIN, A., $1955-$ Some evidence of home range in waterfowl. Trans. N. A. Wildlife Cont., $20: 278-298$.

ORENZ, K., 1941 - Comparative studies on the behaviour of Anatinae. (Translated by Dr. C. H. D. Clarke) Avicultural Magazine, special reprint, 1952,87 pp.

DITOR'S NOTE: The most recent Wilson Bulletin, Dec. 1956, has a page of sketches of "The lallard Duck Courtship Display" by E. Carey Kenny and an interesting article on "Seasonal atterns in the epigamic displays of some surface-feeding ducks" by A. Ogden Ramsay that pplement Mr. Dzubin's valuable cbservations. 